\title{
Celebration of 40 Years of the Journal of Consumer Policy and What the Next 40 Might Look Like
}

The Journal of Consumer Policy (JCP) was established in 1977 under the leadership of Professors Folke Ölander, Norbert Reich, and Gerhard Scherhorn. The three founding editors had a vision of establishing an international scholarly journal that encompassed a diverse range of issues focused on the consumer in the marketplace. In its early years, it became clear that the interplay of research in the social sciences and the study of law would lead to significant insights that could shape consumer well-being and be a guide to those that develop regulations, laws, and policy to serve the consumer interest.

\section{The Evolution of the Editorial Team and the Strategic Use of Special Issues}

Though the founders of the journal were from institutions in just two countries (Denmark and Germany), the editorial board and the content of the articles published in the journal were, from the outset, from all over the world. This was no coincidence. From inception, the journal was intended to be an outlet for developments in consumer policy throughout the world. The co-editors and the editorial board have consistently reflected this diversity. All readers of the journal are indebted to the insights, hard work, and dedication that the past members of the team put in to establish the journal and keep it at the forefront of international consumer policy.

What has all along been clear to the past and current editorial teams is that editors of the journal are not simply gatekeepers of quality for papers submitted to the journal. While this is an important task with which the editors are charged, a fundamental additional responsibility is to foresee the emerging issues that are arising in consumer markets and to shape the types of papers that get submitted in the first place. This is done in two important ways. First, the expertise of the editors and the areas of research they are known for tends to influence the flow of manuscripts to the journal. Second, the JCP has a long tradition of publishing special issues and these help define and shape the focus of the journal. The remainder of this section describes the changing nature of the editorial team followed by an analysis of the special issues published in the journal in the last 20 years.

\section{The Editorial Team}

Table 1 summarizes the evolving team of editors during its first 40 years. As the fields of law, economics, and the behavioral sciences were going through rapid changes and becoming more 
melded with each other, the journal responded by augmenting the original editorial team with additional expertise in the legal aspects of consumer affairs. Professor Geoffrey Woodroffe was added to the mix of editors, which expanded the geographical reach of the team to the UK, and this group flourished for a long period of time. The first of the founding editors to leave the journal was Gerhard Scherhorn, who was replaced for a short period of time by Professor Jörg Finsinger, from the University of Vienna. Professor Mathios, from Cornell University, who remains one of the editors, extended the reach of the editorial board to the USA, replacing Professor Finsinger in 1997. As the founding members ebbed into their retirement, new editors were added to the team and these editors greatly enhanced and accelerated the journals focus on sustainability research, behavioral economics, and the globalization of consumer markets. Professor Stephen Weatherill was added to the team when Norbert Reich retired from the Journal. The transition from 2005 to 2006 was a key moment for the journal. A generational transition occurred. Professor Folke Ölander, the last of the founding editors to still be serving as editor, retired from this position. Given his long standing influence on the Journal, his retirement was a very symbolic moment. His vision for the journal had stood the test of time, and from our personal relationships with him, we know how pleased he was to see that JCP was on solid footing and would continue to thrive for years to come. At the same time, Professor Woodroffe, who was the first additional editor after the founding trio, also stepped down as editor. So for the first time, as can be seen from Table 1, two editors were replaced simultaneously.

Table 1 The Editors of the Journal of Consumer Policy over four decades

\begin{tabular}{|c|c|c|}
\hline Years & Editorial team & Universities represented \\
\hline \multirow[t]{3}{*}{ 1977-1989 } & Folke Ölander & Aarhus School of Business (Denmark) \\
\hline & Norbert Reich & University of Bremen (Germany) \\
\hline & Gerhard Scherhorn & University of Hohenheim (Germany) \\
\hline \multirow[t]{4}{*}{ 1990-1995 } & Folke Ölander & Aarhus School of Business (Denmark \\
\hline & Norbert Reich & University of Bremen (Germany) \\
\hline & Gerhard Scherhorn & University of Hohenheim (Germany) \\
\hline & Geoffrey Woodroffe & Brunel University (UK) \\
\hline \multirow[t]{4}{*}{ 1996-1997 } & Jorg Finsinger & University of Vienna (Austria) \\
\hline & Folke Ölander & Aarhus School of Business (Denmark) \\
\hline & Norbert Reich & University of Bremen (Germany) \\
\hline & Geoffrey Woodroffe & Brunel University (UK) \\
\hline \multirow[t]{4}{*}{ 1998-2000 } & Alan Mathios & Cornell University (USA) \\
\hline & Folke Ölander & Aarhus School of Business (Denmark) \\
\hline & Norbert Reich & University of Bremen (Germany) \\
\hline & Geoffrey Woodroffe & Brunel University (UK) \\
\hline \multirow[t]{4}{*}{ 2001-2005 } & Alan Mathios & Cornell University (USA) \\
\hline & Folke Ölander & Aarhus School of Business (Denmark) \\
\hline & Stephen Weatherill & University of Oxford (UK) \\
\hline & Geoffrey Woodroffe & Brunel University (UK) \\
\hline \multirow[t]{4}{*}{ 2006-2008 } & Alan Mathios & Cornell University (USA) \\
\hline & Lucia Reisch & Copenhagen Business School (Denmark) \\
\hline & John Thøgersen & Aarhus School of Business (Denmark) \\
\hline & Stephen Weatherill & University of Oxford (UK) \\
\hline \multirow[t]{5}{*}{ 2009-Present } & Alan Mathios & Cornell University (USA) \\
\hline & Lucia Reisch & Copenhagen Business School (Denmark) \\
\hline & Hans Micklitz & European University Institute (Italy) \\
\hline & John Thøgersen & Aarhus University (Denmark) \\
\hline & Christian Twigg-Flesner & Universities of Hull (2009-2017) and Warwick (2017-) (UK) \\
\hline
\end{tabular}


The two new editors were John Thøgersen and Lucia Reisch and - together-they began to accelerate and further bring the emerging issues in sustainability to the pages of JCP. Another key transition year was 2008-2009. Professor Hans Micklitz joined the team replacing Steve Weatherill, and an additional editor was added, Professor Christian Twigg-Flesner from the University of Hull (now the University of Warwick). This added significant heft to the team's expertise in European and, more importantly, international consumer law-essential for consumer policy in a global marketplace.

Table 1 summarizes the evolving team of editors.

\section{Special Issues and Emerging Topics in Consumer Policy}

Throughout its history, JCP has used special issues to identify emerging topics/ themes in its domain. The titles of these are presented in Table 2. The titles suggest that the Journal does tend to foresee the future topics that will arise in consumer markets. The rise of the Euro was focused on in 1999, years before it was introduced as a currency. The relationship between biotechnology and the consumer was a focus of the journal just as Europe and the USA were taking different approaches to regulating the use of such technology in consumer markets. What becomes evident from examining the titles of the special issues is the focus of the journal on environmental/sustainability issues. Eight special issues have been specifically focused on these topics with several focused on the environment and behavioral economics. Even beyond the special issues the JCP has published dozens and dozens of articles focused on the relationship between consumer behavior and sustainability. The journal is proud of its place in this space especially during the earlier years when both sustainability research and behavioral economics were more on the fringe than in the mainstream. Table 2 also reveals the breadth of consumer topics covered by the Journal including a focus on financial services, product quality, children as consumers, disadvantaged populations, healthcare, the digital age, the media, etc.

The use of the special issue has been a strategic choice made by the editors to feature and set the research agendas for rapidly changing areas in the consumer domain. The fact that there were 23 special issues in just the last 18 years of the journal demonstrates how dramatic the rate of change is in consumer policy. We fully expect this to continue as we enter years 41 and beyond.

\section{Analysis of Citations to Identify the Topics that Influenced the Literature}

Another key indicator of the impact of JCP is to examine the content areas of the articles that have been most cited by other researchers. Table 3 presents the titles of the papers that, according to a Google Scholar search, received over 200 citations (in order of the number of citations).

The papers listed in Table 2 reveal a few interesting themes. First, the roles and the responsibility of the consumer in broad environmental and sustainability issues emerge as an important thread of the literature. This includes, for example, compulsive and/or addictive buying, which constitute five of the 16 most cited papers in the journal's history. Second, the role that labelling plays in remediating the information asymmetry between producers and consumers is prominent in the most highly cited papers in the journal. Three of the papers in 
Table 2 Special issues and emerging topics in consumer policy

Year Title of special issue

1998 Biotechnology and the Consumer

1999 The Euro: Consequences of the Consumer and the Citizen

1999 Environment and Consumer Policy: Part 1. Perspectives from Economics and Behavioral Science

2000 Environment and Consumer Policy: Part 2. Perspectives from Legal Science

2002 Law, Information and Product Quality

2003 Norwegian Research on Sustainable Consumption

2003 Consumers, Families, and Markets in Transition

2004 The Protection of the Weak Party in a Harmonised European Contract Law

2006 Consumers, Information, and the Evolving Healthcare Market Place

2006 The Politics of Necessity

2007 Shopping for Human Rights

2007 Effects of the Euro Changeover on Consumer Behavior

2008 The iConsumer and the Role of Consumer Law

2008 The Consumer, the European Union, and Media Law

2010 Time Allocation, Consumption, and Consumer Policy

2011 Putting Sustainable Consumption into Practice

2011 Behavioural Economics, Consumer Policy, and Consumer Law

2012 From Knowledge to Action-New Paths Towards Sustainable Consumption

2012 The Regulation of Over-Indebtedness of Consumers in Europe

2013 From Rule Export to Institution Building: Consumer Law at the EU's Doorstep

2014 Consumer Socialization, Buying Decisions, and Consumer Behaviour in Children

2015 Behavioural Economics, Environmental Policy and the Consumer

2015 Conceptualizing the Consumer of Financial Services: A New Approach?

2016 Sustainable Textiles: The Role of Consumers, Civil Society, Corporations, and Government
Editors of special issue

Alan Mathios

Thierry Vissol

Folke Ölander, Norbert Reich, John Thøgersen

Folke Ölander, Norbert Reich, John Thøgersen

Christian Twigg-Flesner, Stephen

Weatherill, Chris Willett

Folke Ölander, Lucia Reisch

Pirjo Laaksonen, Johanna Leskinen, Alan Mathios, Folke Ölander

Stephen Weatherill

Will White

Bronen Morgan, Frank Trentmann

Michele Micheletti, Andreas Follesdal

John Thøgersen, Tommy Gärling

Natali Helberger, Christian Twigg-Flesner

Allison Harcourt, Stephen Weatherill

Wencke Gwozdz, Lucia Reisch, Alfonso

Sousa-Poza

John Thøgersen, Ulf Schrader

Lucia Reisch, Hans Micklitz, Kornelia Hagan

John Thøgersen, Ulf Schrader

Hans Micklitz

Yane Svetiev

Gunnar Mau, Hanna Schramm-Klein, Lucia Reisch

Lucia Reisch, Cass Sunstein

Lorna Fox O’Mahony, Folarin Akinbami

Magnus Boström, Michele Micheletti

Table 3 have the world "label" in their titles and several other papers have content that relates directly to the role of labels in consumer markets. Finally, the popularity of these papers reinforces the notion that the fields of environmental policy and consumer policy are no longer distinct but essentially intertwined with each other.

\section{Future Directions for JCP}

In this section, we take the liberty of forecasting which topics are likely to emerge in the future pages of JCP. The first section provides some broad themes we expect to see emerge from a social science perspective followed by a second section which focuses specifically on 
Table 3 Most cited papers in the Journal of Consumer Policy (over 200 citations)

Year Title of paper Authors

2001 Determinants of Consumer Attitudes and Purchase Intentions

L. Bredahl

With Regard to Genetically Modified Food-Results of a

Cross-National Survey

2001 Economics of Food Labeling

1996 I'd Like to Buy the World a Coke: Consumptionscapes of the "Less Affluent World"

1999 Information, Incentives, and Proenvironmental Consumer Behavior

1988 Compulsive Buying: Concept and Measurement

2003 Converging Conventions of Comfort, Cleanliness and Convenience

1994 Addictive Consumption: Function and Fragmentation in Postmodernity

1997 The Use of Quality and Reputation Indicators by Consumers; The Case of Bordeaux Wine

1995 Understanding of Consumer Behavior as a Prerequisite for Environmental Protection

2003 Mobile Phone Use as Part of Young People's Consumption Styles

2005 The Reliability of Certification: Quality Labels as a Consumer Policy Tool

1990 An Inquiry into the Compulsive Side of "Normal" Consumers

2005 How may consumer policy empower consumers for sustainable lifestyles?

1990 Addictive Buying in West Germany: An Empirical Study

2000 Psychological Determinants of Paying Attention to Eco-Labels In Purchase Decisions: Model Development and Multinational Validation

2006 Consumer Power: a Comparison of the Old Economy and the Internet Economy

1999 The Ethical Consumer. Moral Norms and Packaging Choice

1988 Compulsive Consumption and Credit Abuse

E. Golan, F. Kuchler, L. Mitchell, C. Greene

G. Ger, H.W. Belk

P.C. Stern

G. Valence, A. d'Astous, L. Fortier

E. Shove

R. Elliott

S. Landon, C.E. Smith

F. Ölander, J. Thøgersen

T.A. Wilska

G. Jahn, M. Schramm, A. Spiller

A. d'Astous

J. Thøgersen

G. Scherhorn, L. Reisch, G. Raab

J. Thøgersen

B. Rezabakhsh, D. Bornemann, U. Hansen, U. Schrader

J. Thøgersen

R.J. Faber, T.C. O'Guinn

2009 Simple and Painless? The Limitations of Spillover in Environmental Campaigning

1998 Consumer Attitudes and Decision Making With Regard to Genetically Engineered Food Products - A Review of the Literature and a Presentation of Models for Future Research

2005 Music Piracy on the Web-How Effective Are Anti-Piracy Arguments? Evidence from the Theory of Planned Behaviour

2005 Sustainable Consumption Governance: A History of Promises and Failures

J. Thøgersen, T. Crompton

L. Bredahl, K.G. Grunert, L.J. Frewer

A. d'Astous, F. Colbert, D. Montpetit

D. Fuchs, S. Lorek

2003 Participation in Philanthropic Activities: Donating Money and Time W. K. Bryant, H. Jeon-Slaughter, H. Kang, A. Tax

Note: Compiled 10 June, 2017

Consumer Law. These sections are, of course, interrelated with each other and increasingly over time are blending with each other.

\section{Emerging Themes}

\section{Environmental Policy and Consumer Policy Will Further Be Intertwined}

In our view, the confluence and interconnectedness of environmental and consumer policy is a fortunate development that will continue and accelerate. Some of the most pressing global issues are related to the overlap of consumption and environmental sustainability. For example, 
implementation of a carbon tax to address climate change - once a very remote possibilitycontinues to gain the attention of scientists, law makers, and policy analysts. This is not the proper venue to debate whether the social benefit of a carbon tax exceeds the costs of a tax. However, much can be learned from consumer policy theory in terms of how best to implement and communicate about such a tax should governments decided to utilize one. Throughout the pages of the JCP are a number of articles that directly contribute to our understanding of the relationship between consumer behavior and government attempts to alter such behavior via labelling, pricing, or other mechanisms.

In particular, academic research that addresses consumer behavior, addictive behavior, consumer responses to labels, and consumer responses to prices all feed into the research needs required to evaluate tax and regulatory policies designed to protect the environment. The recent focus of the JCP on behavioral economics and the law will shape how best to evaluate the impact of environmental regulation on consumer and firm behavior and thus ultimately the climate. Research on the economics of information, law and behavioral economics, price and non-price mechanisms for behavioral change will be needed.

The international focus of the JCP will also shape its future directions. With the broad global focus of the journal, we expect to publish research that compares and contrasts how different countries implement policies designed to both protect the environment and promote sustainable consumption and production. These policies are likely to be key drivers of longterm economic well-being with significant repercussions from over or under regulation in this arena. Hopefully, the JCP can be a home for research that can inform best practices and help distinguish policies and practices that are effective from those that appear good on paper but do not have the intended effect or have serious unintended consequences. Global variations in labelling policy, taxation, social norms, and other key drivers of environmental/consumer behavior are likely to be described and analysed in future issues of the journal.

\section{An Increased Focus on Technology and Privacy}

Technology and its role in consumer markets is another rapidly changing area that is likely to be the focus of JCP in the future. Information about the quality of consumer goods can be much more easily obtained but issues of the reliability of the various information sources raise fascinating and important consumer policy questions. While technology can equalize opportunity for information to be utilized by more consumers, it is also the case that vulnerable consumers can be more easily targeted by deceptive and outright scams. How governments respond, what types of market mechanisms develop to distinguish between high quality information and low quality information are all areas ripe for further research and exploration.

Information technology is now embedded in a significant share of consumer products and the regulation of privacy of information associated with the ordinary use of these products is raising new issues. Take, for example, the typical car, which is the focus of a recent workshop offered by the US Federal Trade Commission. In describing the workshop the FTC notes: "Modern motor vehicles increasingly are being equipped with technologies that enable them to access information via the Internet and gather, store, and transmit data for entertainment, performance, and safety purposes. Automated vehicles, vehicles with vehicle-to-vehicle communications technology, and other connected vehicles (i.e., with some form of wireless connectivity) can provide important benefits to consumers and have the potential to revolutionize motor vehicle safety. At the same time, these automated and connected vehicles are expected to generate an 
enormous amount of data, some of which will be personal and sensitive, such as real time precise geolocation data and the contents of driver communications that result when drivers connect their mobile phones to a vehicle's computer system." Obviously, these issues are not limited to cars, but apply to a wide variety of consumer products. We hope that JCP can be a leader in publishing research related to the value of these benefits and the related regulatory and privacy issues associated with the ordinary use of consumer products.

The use of biotechnology and its relationship to consumer well-being is another area that links modern technology with important privacy issues, especially in the area of health policy. Medical advances in the use of precision medicine - where treatments are developed specific to the genetic make-up of specific individuals - hold tremendous promise for population health. At the same time, there are concerns about how information about individual predisposition to disease might impact consumers. The potential use of this information by employers, insurance companies, and others are often at the centre of debates about the regulation of the privacy of this information. Much can be learned from research on consumer markets to address some of these questions. Theories of asymmetric information, long the underpinnings of consumer policy research, have much to offer in this arena. For example, even with strict privacy control of patient health information, employers and insurance companies have mechanisms for consumers to implicitly reveal such information. For once an insurer knows that the consumer knows of their own risk, they can develop a menu of coverage options that cause consumers to self-select into specific contracts. With advances in technology providing consumers more and more information about themselves we expect the JCP to publish work at the interface of privacy, asymmetric information, and consumer outcomes.

\section{An Increased Focus on Free Versus Fair Trade}

The rise of the World Trade Organization in preventing undue protectionism has been a major development in global consumer markets over the last 20 or so years. The tension between free trade agreements and local preferences for particular aspects of the way a product is produced continues to be a contentious issue. For example, if a country bans products that are produced with a particular technology does it reflect valid consumer preferences or is the ban a veil for protectionism? The globalization of markets continues to expand and there is an emerging backlash by several key players in the global marketplace. The Brexit decision along with the recent election of Donald Trump (whose platform was to withdraw from several free trade agreements) are signs that the international context for consumer policy is in flux. Much of the discussion is likely to be based on further articulating and understanding what we mean by fair trade and how best to model the distinction between free and fair trade.

\section{The Future of Consumer Law}

\section{An Increased Focus on the Internationalization of Consumer Law}

For many years, consumer law has been the focus of national and regional discourses, enhanced by comparative discussions at international conferences. However, as highlighted in an editorial in JCP some years ago (Micklitz and Twigg-Flesner 2010), the international dimension of consumer law still does not receive the recognition it deserves. This is despite the 
fact that there has been quite intensive activity by a range of international institutions in this field (Durovic and Micklitz 2017). More comparative work on consumer law is certainly needed to gain a better understanding of how the issues affecting consumers are tackled in different parts of the world. In addition, international influences are increasingly shaping the substance of domestic consumer transactions, e.g., through the way in which international institutions demand that national laws are structured as a precondition for receiving support from that institution. At the same time, the volume of international consumer transactions is rising, not only because consumers are able to acquire goods and services online, but - as noted elsewhere in this editorial - consumers increasingly acquire digital content. Such content can be supplied from anywhere in the world without difficulty - there is no cost issue of sending digital information around the globe, in contrast with goods or services. Hence, the main focus for consumer law scholarship in the future will have to be the international - or, perhaps, "transnational"-dimension.

The regional approach of "enforced" harmonization of national laws, e.g., within the European Union, seems insufficient. Perhaps the time has come for international-level regulation of some types of consumer transactions. This requires scholarship on the extent to which it is both possible and feasible to adopt a global legal framework to govern all international consumer transactions. Of course, such research might reveal that international issues could be addressed in ways which have not yet been considered at all. Consumer Law scholarship needs to become international in its outlook.

\section{Who Is the Consumer the Law Is Protecting, and Who Is the Consumer the Law Should be Protecting?}

A much more fundamental issue which consumer law needs to tackle is the kind of consumer who ought to be the focus of protection. A long-running debate in the context of EU Consumer Law is the use of the "average consumer" yardstick, which is defined as a "reasonably wellinformed consumer and reasonably observant and circumspect," with some allowance made for social, cultural or linguistic factors. ${ }^{2}$ The literature criticizing this for being an unrealistically normative standard is voluminous, with valuable insights from behavioural economics (including several key articles published in the $J C P$ ) demonstrating that the way consumers actually behave is a long way removed from this ideal-type. This leaves a dilemma; however, consumers are a heterogeneous group, ranging from the very vulnerable to the very capable. "Vulnerability" itself is a label which has been much debated - it ranges from situational and short-term vulnerability (e.g., the recently bereaved) to long-term/permanent vulnerability linked to the attributes of an individual (e.g., someone with a learning disability). However, criticizing the "average consumer" notion does not solve the question of whether consumer law needs some kind of reference point for a "typical consumer," and how this should be defined. Behavioural economics might offer some useful pointers in this regard. But one could go further: consumers enjoy strong levels of protection, whether they need it or not - their rights attach to the status of falling within the definition of "consumer." Many rules of consumer law are justified on the basis that a consumer is a weaker party vis-à-vis a trader, and there are often specific rationales for the introduction of certain rules. The right of

\footnotetext{
${ }^{1}$ Case C-210/96 Gut Springenheide v Tusky [1998] ECR I-4657, paragraph 31.

2 Case C-220/98 Estée Lauder Cosmetics GmbH \& Co. OHG v Lancaster Group GmbH [2000] ECR I-117, paragraph 29.
} 
withdrawal in EU Law for off-premises contracts is justified on the basis that a consumer "may be under potential psychological pressure or may be confronted with an element of surprise,"3 yet it is not required that a consumer has to show that a contract was in fact concluded in such circumstances. ${ }^{4}$ Any consumer enjoys these rights, even those that are anything but in a weaker position and have excellent negotiation abilities. ${ }^{5}$ So perhaps it is necessary to develop a more nuanced approach to consumer law, where those in real need of protection do get this, but those who are capable to deal with traders on the same level might not benefit from all the rights granted to consumers merely because of their status as "consumer." Put differently, should consumer law move away from focusing on supporting the confident consumer and recognize that the poor and/or vulnerable consumers are in real need of protection, with the effect that those in need are put at the centre of consumer law, while those better placed to look after themselves are required to take greater responsibility for themselves? In other words, can we finally find a way so the poor no longer pay more (Caplovitz 1963)? Whether such an approach is appropriate and even feasible certainly requires further debate.

\section{Consumer Law in the Digital World}

Digitalization has grown steadily over the last 20 years, but it has taken a while before the transformative effect of this process on the economy and on society has become clear. Today, one of the key questions is whether digitalization is just another technology in the evolutionary process of the economy or whether digitization has a disruptive effect (Brownsword 2016). In the latter case, this will prompt the need for fresh thinking about the economy and society. In consumer law, one of the key issues is the fact that consumer law is based on the respective status of the participants. Irrespective of whether the consumer image is the responsible, the confident or the vulnerable consumer, or indeed any other consumer image, the legal rules are tied to the legal definition of what makes someone a "consumer." But does this still hold true in the digital world? Is it still possible to draw a clear distinction between the consumer and the supplier in a world where the line between consumption and production become increasingly blurred?

The use of algorithms and the prospects opened up by self-learning algorithms which update the source code raises questions of an altogether different dimension. The issue here is not only one of maintaining the autonomy of consumers, which was to be the driver behind potential solutions as regards the law of digital services, but of human dignity in the age of artificial intelligence (AI). The political challenge is to answer the question of how to ensure that self-learning algorithms "act" in an ethically responsible manner. Can politics trust in business, in competition, in independent ethical behaviour on the part of those who are responsible for driving forward developments when it comes to AI? An even more challenging question is what will happen when AI takes on a life of its own - how can a self-controlling process be politically, ethically and legally mainstreamed?

The editors of JCP believe that it is the political realm which is called to act. The question is no longer whether political action is necessary, but what sort of action is needed. A normative component needs to be incorporated into the algorithms. Under the lofty rubric of "human dignity" and the autonomy of human beings, the issue

\footnotetext{
${ }_{3}$ Recital 21 of the Consumer Rights Directive (2011/83/EU).

${ }^{4}$ C-423/97 Travel Vac SL v Sanchis [1999] ECR I-2195.

${ }^{5}$ Cf. the UK Supreme Court's ruling in Robertson v Swift [2014] UKSC 50.
} 
when it comes to consumer law would be compliance with the prohibition of discrimination, fair advertising, consumer data protection law and fair contract terms and conditions. Can this task be managed within the consumer law 1.0 or do we need a different consumer law, one that is able to tackle all the open questions on how transactions are organized via the internet, often without a contract (in the traditional sense) and how they can be enforced. We will find a series of obstacles strewn across the path towards implementation of autonomy and human dignity which have their origin in the different rationality behind law and technology (Boer 2009).

\section{Conclusions}

The current editors are proud and honoured to be leading JCP at a time when it can celebrate its 40-year track record of shaping debates across the spectrum of consumer policy and consumer law, and excited about what lies ahead. Developments in environmental policy, the seemingly unstoppable rise of digital technology and the continuing trend towards a global consumer marketplace will all be focal areas for JCP over the coming years and we are keen to receive original contributions in these areas. However, JCP remains a home for original research on all aspects of consumer policy and law from around the world, and we look forward to the extensive variety of manuscripts that will be submitted to JCP in the future. For now, we raise a (digital) glass to JCP to say "Happy 40th Birthday" and "many happy returns."

Alan Mathios, Cornell University, Ithaca, NY, USA

Hans Micklitz, European University Institute, Fiesole, Italy

Lucia Reisch, Copenhagen Business School, Copenhagen, Denmark

John Thøgersen, Aarhus University, Aarhus, Denmark

Christian Twigg-Flesner, University of Warwick, Coventry, UK

\section{References}

Boer, A. (2009). Legal theory, sources of law, and the semantic web. Amsterdam: IOS Press.

Brownsword, R. (2016). The E-commerce directive, consumer transactions, and the digital single market: Questions of regulatory fitness, regulatory disconnection and rule redirection. Estonia: Lecture given at a SECOLA Conference in Tartu.

Caplovitz, D. (1963). The poor pay more: Consumer practices of low-income families. New York: Free Press of Glencore.

Durovic, M., \& Micklitz, H. (2017). Internationalization of consumer law: A game changer. New York: Springer. Micklitz, H., \& Twigg-Flesner, C. (2010). Editorial: Think global-Towards international consumer law. Journal of Consumer Policy, 33, 201-207. 